\title{
Synthesis, characterization and application of an inorgano organic material: $p$-chlorophenol anchored onto zirconium tungstate
}

\author{
BEENA PANDIT and UMA CHUDASAMA* \\ Department of Applied Chemistry, Faculty of Technology and Engineering, M.S. University of Baroda, \\ Vadodara 390 001, India
}

MS received 3 August 2000; revised 1 March 2001

\begin{abstract}
Tetravalent metal acid (TMA) salt zirconium tungstate (ZW) has been synthesized, followed by its derivatization using para-chlorophenol $(p \mathrm{CP})$. The resulting compound is abbreviated as $\mathrm{ZWpCP}$. $\mathrm{ZW} p \mathrm{CP}$ has been characterized for elemental analysis, spectral analysis (FTIR), X-ray analysis and thermal analysis (TGA). Its chemical stability has been assessed in various mineral acids, bases and organic solvents. Ion exchange capacity (IEC) has been determined and distribution behaviour towards several metal ions in different electrolyte solutions with varying concentrations has been studied and a few binary separations achieved.
\end{abstract}

Keywords. Tetravalent metal acid salts; derivatized TMA salts; hybrid materials; inorgano-organic materials.

\section{Introduction}

There is currently high interest in engineering mixed materials (organic/inorganic) where features of the organic and inorganic components complement each other leading to the formation of new solid-state structures and materials with new composite properties. Some examples of recent interest are inorganic solids with organic intercalates (Bringley and Averill 1990), zeolites and open framework host materials with organic guests (Ozin 1992) and thin film heterostructures built up from alternating layers of organic poly electrolytes and colloidal inorganic polyions (Keller et al 1994; Kleinfield and Ferguson 1994). New inorganic lattice structures are formed, resulting from cooperative interactions between the organic and inorganic components. In all cases, there is promise of developing new materials with properties not seen in purely organic or purely inorganic solids.

Inorganic ion exchangers of the class of tetravalent metal acid (TMA) salts can be obtained in both, amorphous and crystalline forms (Amphlett 1964; Clearfield and Stynes 1964; Varshney and Khan 1991). These compounds have the general formula $\mathrm{M}(\mathrm{IV})\left(\mathrm{HXO}_{4}\right)_{2} \cdot n \mathrm{H}_{2} \mathrm{O}$, where $\mathrm{M}(\mathrm{IV})=\mathrm{Zr}, \mathrm{Ti}, \mathrm{Th}, \mathrm{Ce}, \mathrm{Sn}$, etc and $\mathrm{X}=\mathrm{P}, \mathrm{Mo}, \mathrm{W}$, $\mathrm{As}, \mathrm{Sb}$, etc. The protons contained in the structural hydroxyl groups can be exchanged with several cations and thus these materials behave as cation exchangers.

TMA salts can be derivatized by organic moieties bearing ionogenic groups such as $-\mathrm{OH},-\mathrm{COOH},-\mathrm{SO}_{3} \mathrm{H}$ etc which also act as ion exchangers. These compounds

*Author for correspondence are known as inorgano-organic ion exchangers or derivatized tetravalent metal acid (DTMA) salts (Alberti et al 1978, 1980, 1982).

Interest in the DTMA salts stems from the fact that the inorganic backbone provides a stable and relatively inert anchor for the organic moiety. DTMA salts have the added advantage of both their counterparts in terms of thermal and chemical stability and ion exchange capacity. Derivatization of the inorganic ion exchangers by organic molecules depends on the nature of the inorganic matrix. In layered materials the organic molecules are incorporated within the layers (Costantino et al 1986), whereas in non layered materials the organic molecules get either anchored, sorbed on the surface or get encapsulated within the pores of the matrix. Preparation of organic derivatives of inorganic TMA salts has been thoroughly studied (Alberti et al 1978, 1980, 1982), by intercalation of polar organic molecules such as alcohols, glycols, acetone, urea and its derivatives or molecules of biopharmaceutical interest such as amino acids, heterocyclic bases etc (Behrendt et al 1976; Costantino 1979; Szirtes et al $1988)$ within the layers of crystalline $\alpha$-zirconium phosphate $(\alpha-Z r P)$.

In $\alpha$-ZrP three oxygens of each phosphate group are bonded to three different zirconium atoms while the fourth oxygen bears the exchangeable proton that can be replaced by other cations. Compounds with the $\equiv \mathrm{P}-\mathrm{R}$ or $\equiv \mathrm{P}-\mathrm{OR}$ groups $(\mathrm{R}=$ organic alkyl/aryl radicals such as $\mathrm{H}_{2} \mathrm{O}_{3} \mathrm{P} \cdot \mathrm{CH}_{2} \mathrm{OH} / \mathrm{H}_{2} \mathrm{O}_{3} \cdot \mathrm{PC}_{6} \mathrm{H}_{5}$ ) are reported (Alberti et al 1985; Alberti and Costantino 1991).

Apart from the fundamental aspects, there is an increasing interest in the potential applications of inorganoorganic ion exchangers. According to the nature of the $\mathrm{R}$ 
group, different applications in the field of chromatographic separation (Alberti and Costantino 1991), catalysis (Alberti et al 1993a), photochemistry (Vermuelen and Thompson 1992), protonic conduction (Alberti and Casciola 1997; Alberti et al 1993b), are possible. Organic derivatives are used as supports in gas chromatography, thin layer chromatography and molecular sieves (Alberti et al 1993a). The loading potential of the inorganic backbone is as high as two alkyl groups per zirconium atom, which is a distinct advantage over commercial reverse phase chromatography supports. Besides, inorgano-organic materials are known to have a large selectivity for mono and multivalent cations (Costantino 1979).

Organic derivatives of layered $\alpha-\mathrm{ZrP}$ can be termed as intercalation compounds or lamellar compounds. In case of $\gamma$ - ZrP however, derivatization takes place through a topotactic reaction which consists of the substitution of $\mathrm{O}_{3} \mathrm{POH}$ tetrahedra in a preformed layered phosphate by $\mathrm{O}_{3} \mathrm{PR}$ tetrahedra, whilst retaining the original layered structure (Alberti 1990; Alberti et al 1992, 1993b). Using this method, substitution of the $\mathrm{OH}$ by $\mathrm{R}$ groups (Alberti et al 1994) takes place as follows:

$$
\mathrm{M}(\mathrm{IV})\left(\mathrm{HPO}_{4}\right)_{2}+2 \mathrm{RPO}_{3} \mathrm{H}_{2} \stackrel{\leftarrow}{\rightarrow} \mathrm{M}(\mathrm{IV})\left(\mathrm{RPO}_{3}\right)_{2}+2 \mathrm{H}_{3} \mathrm{PO}_{4}
$$

In the present endeavour, an attempt has been made to synthesize an inorgano-organic material $\mathrm{ZW} p \mathrm{CP}$, by derivatizing the TMA salt zirconium tungstate (ZW) with an organic moiety para-chlorophenol ( $p \mathrm{CP})$.

$\mathrm{ZW} p \mathrm{CP}$ has been characterized for elemental analysis, spectral analysis (FTIR), X-ray analysis and thermal analysis (TGA). Ion exchange capacity (IEC) has been determined and the effect of heating on IEC has been studied. Distribution coefficient $\left(K_{\mathrm{d}}\right)$ for several metal ions has been determined in various electrolyte solutions of varying concentrations, on the basis of which metal ion separations viz. $\mathrm{Co}$ (II) from $\mathrm{Cu}$ (II), $\mathrm{Zn}$ (II) and $\mathrm{Pb}$ (II), has been achieved.

\section{Experimental}

\subsection{Preparation of zirconium tungstate $(Z W)$}

ZW was prepared by adding an aqueous solution of sodium tungstate to an aqueous solution of zirconium oxychloride in $2: 1$ molar proportion, dropwise and with constant stirring. After complete addition of sodium tungstate, the solution alongwith the precipitates was stirred for $2 \mathrm{~h}$ more. The precipitates were filtered, washed with conductivity water till the washings were chloride free, and dried at $\sim 40^{\circ} \mathrm{C}$. The dried precipitates were sieved to the desired particle size (30-60 mesh). The sample was then converted to the hydrogen form by immersion in $1 \mathrm{M} \mathrm{HCl}$, the acid being intermittently replaced. It was then washed repeatedly with conductivity water till free of chloride ion and finally dried at $40^{\circ} \mathrm{C}$. The yield of the product was $\sim 90 \%$.

\subsection{Preparation of organic derivative $(\mathrm{ZWpCP})$}

$\mathrm{ZW} p \mathrm{CP}$ was prepared by heating under reflux for $\sim 2 \mathrm{~h}$, $1 \mathrm{~g}$ of the acid treated ZW with $20 \mathrm{ml}$ of pure distilled $p$ chlorophenol. The excess of the organic reagent was decanted. This was followed by washing the sample with alcohol and finally drying it at $\sim 40^{\circ} \mathrm{C}$. The amount of $p \mathrm{CP}$ anchored onto $\mathrm{ZW}$ was estimated as the difference between the initial and final concentration by the bromination method (Vogel 1989).

\subsection{Characterization}

Zirconium and tungsten in $\mathrm{ZW}$ and $\mathrm{ZWpCP}$ were estimated gravimetrically as zirconium oxide by cupferron method (Elving and Olson 1955) and as barium tungstate (Vogel 1978) respectively. Carbon and hydrogen in ZWp CP were determined using a Coleman analyser model 33. Thermograms (TGA) were recorded on a Shimadzu DT-30 thermal analyser at a heating rate of $10^{\circ} \mathrm{C} \mathrm{min}{ }^{1}$. FTIR spectra were recorded on a Perkin Elmer model 1720X equipped with Epson Hi 80 printer/plotter. Sample preparation was done using $\mathrm{KBr}$ as reference with $1 \%$ sample concentration. X-ray analysis of ZW as well as $\mathrm{ZWpCP}$ were carried out on a X-ray diffractometer, Rigaku Dmax-30 using $\mathrm{CuK}_{\alpha}$ radiation with a nickel filter.

Chemical stability of $\mathrm{ZWpCP}$ was assessed in several mineral acids such as $\mathrm{HCl}, \mathrm{HNO}_{3}$ and $\mathrm{H}_{2} \mathrm{SO}_{4}$; bases such as $\mathrm{NaOH}$ and $\mathrm{KOH}$; and organic solvents such as alcohol, acetone and diethyl ether. $500 \mathrm{mg}$ each of $\mathrm{ZWpCP}$ was taken in $50 \mathrm{ml}$ of different solvents and kept for $24 \mathrm{~h}$ and the changes in colour, nature and weight of the sample were noted.

IEC was determined by the column method (Nabi and Rao 1981). The effect of heating on IEC was studied by heating the exchangers at various temperatures in the range $100-500^{\circ} \mathrm{C}$ for $2 \mathrm{~h}$ each in a muffle furnace.

\subsection{Distribution studies}

Distribution coefficient $\left(K_{\mathrm{d}}\right)$ for transition metals such as $\mathrm{Zn}(\mathrm{II}), \mathrm{Cu}(\mathrm{II}), \mathrm{Ni}(\mathrm{II}), \mathrm{Mn}(\mathrm{II}), \mathrm{Co}(\mathrm{II})$, heavy metals $\mathrm{Pb}(\mathrm{II})$, $\mathrm{Bi}(\mathrm{III}), \mathrm{Hg}(\mathrm{II})$ and rare earths $\mathrm{La}(\mathrm{III}), \mathrm{Ce}(\mathrm{IV}), \mathrm{Th}(\mathrm{IV})$ were determined.

$$
K_{\mathrm{d}}=\frac{1-F}{F} \cdot \frac{V}{W}\left(\mathrm{ml} \mathrm{g}^{-1}\right),
$$

where $I$ is the amount of the metal ion in solution, $F$ the final amount of the metal ion in solution, $V$ the volume of the metal ion solution taken for analysis ( $\mathrm{ml})$ and $W$ the weight of the exchanger taken for analysis $(\mathrm{g})$. 
The ion exchanger $(0 \cdot 1 \mathrm{~g})$ was equilibrated with a $0.001 \mathrm{M}(20 \mathrm{ml})$ metal ion solution at room temperature for $24 \mathrm{~h}$ with intermittent shaking. The uptake of the metal ion was determined as a difference in the initial and the final concentrations of the metal ion using EDTA as a titrant. Distribution studies were also carried out for all the above mentioned metal ions in different electrolyte media such as $0.001 \mathrm{M}, 0.1 \mathrm{M}, 0.4 \mathrm{M} \mathrm{HNO}_{3}$ and $0.05 \mathrm{M}$, $0 \cdot 5 \mathrm{M}$ and $1 \mathrm{M} \mathrm{NH}_{4} \mathrm{NO}_{3}$ solutions.

\subsection{Metal ion separations}

For binary separations, $5 \mathrm{~g}$ of the ion exchanger in $\mathrm{H}^{+}$ form was taken in a glass column $(30 \times 1 \cdot 1 \mathrm{~cm} \mathrm{dia})$. The column was washed thoroughly with deionized water and the mixture to be separated was loaded on it maintaining a flow rate of $0.5 \mathrm{ml} \mathrm{min}{ }^{-1}$. In all the separations, the cation concentration was maintained at $0.001 \mathrm{M}$ concentration and $5 \mathrm{ml}$ of each metal ion solution was taken.

\section{Results and discussion}

Chemical analysis indicates the composition of $\mathrm{Zr}: \mathrm{W}$ to be $1: 2$. Based on this and the TGA data, the formula for $\mathrm{ZW}$ can be proposed as $\mathrm{Zr}(\mathrm{IV})\left(\mathrm{H}_{2} \mathrm{WO}_{4}\right)_{2} \cdot 8 \mathrm{H}_{2} \mathrm{O}$. The number of water molecules was determined using Alberti's formula (Alberti and Torracca 1972). In case of $\mathrm{ZWpCP}$, elemental analysis indicates $\% \mathrm{C}=5 \cdot 172 ; \% \mathrm{H}=0.530$ (instrumental elemental analysis) and $\% \mathrm{C}=6 \cdot 600 ; \% \mathrm{H}=$ 0.550 (bromination method). $\mathrm{ZWpCP}$, though stable in $\mathrm{HCl}(11.3 \mathrm{~N})$ and $\mathrm{H}_{2} \mathrm{SO}_{4}(36 \mathrm{~N})$, was stable in $\mathrm{HNO}_{3}$ only up to $0.5 \mathrm{~N}$ concentration. $\mathrm{ZWpCP}$ was found to be stable in bases such as $\mathrm{NaOH}$ and $\mathrm{KOH}$ up to $2 \mathrm{M}$ concentration, as evidenced by no change in colour, form or weight of the samples used. $\mathrm{ZWpCP}$ was also found to be stable in ethanol, acetone and diethyl ether.

Derivatization of $\mathrm{ZW}$ with $p \mathrm{CP}$ can be observed visually; when $\mathrm{ZW}$ is treated with $p \mathrm{CP}$, the pale white amorphous ZW turns brownish yellow, which resembles organic resins. This is further confirmed by the FTIR spectra. For reference purpose, the IR spectrum of neat $p \mathrm{CP}$ was taken.

The IR spectrum of $p \mathrm{CP}$ exhibits broad bands in the $3600-3300 \mathrm{~cm}^{-1}$ region, characteristic of the free $-\mathrm{OH}$ stretches. A band at $\sim 3086 \mathrm{~cm}^{-1}$ is attributed to aromatic stretches. Bands at $2100 \mathrm{~cm}^{-1}$ and in the region $\sim 1950$ $1675 \mathrm{~cm}^{-1}$ are attributed to the overtone or combination bands in phenols. Bands between 1600 and $1550 \mathrm{~cm}^{-1}$ are due to the $\mathrm{C}=\mathrm{C}$ stretching, while bands between 1410 and $1310 \mathrm{~cm}^{-1}$ and 1250 and $1150 \mathrm{~cm}^{-1}$ are attributed to the inplane bending of the $\mathrm{C}-\mathrm{H}$ bonds. Bands between 1060 and $1010 \mathrm{~cm}^{-1}$ are attributed to the aryl chloride group and also to the disubstituted benzene ring. Bands between 900 and $600 \mathrm{~cm}^{-1}$ are attributed to the out of plane bending of the ring $\mathrm{C}-\mathrm{H}$ bonds.
The FTIR spectra of ZW (figure 1a) shows broad bands in the $\sim 3400 \mathrm{~cm}^{-1}$ region characteristic of asymmetric and symmetric hydroxo $-\mathrm{OH}$ and aquo $-\mathrm{OH}$ stretching frequency. A sharp medium band at $1620 \mathrm{~cm}^{-1}$ is attributed to the aquo $(\mathrm{H}-\mathrm{O}-\mathrm{H})$ bending.

The FTIR spectrum of $\mathrm{ZWpCP}$ (figure $1 \mathrm{~b}$ ) shows broad bands in the $\sim 3400 \mathrm{~cm}^{-1}$ region, attributed to the $-\mathrm{OH}$ stretches. A sharp medium band at $\sim 1620 \mathrm{~cm}^{-1}$ is attributed to the aquo $\mathrm{H}-\mathrm{O}-\mathrm{H}$ bending and $\mathrm{C}-\mathrm{C}$ in plane stretching frequencies. Bands in the $1500-1400 \mathrm{~cm}^{-1}$ region and very weak bands in the $1300-1200 \mathrm{~cm}^{-1}$ regions are attributed to the in plane bending of the $\mathrm{C}-\mathrm{H}$ bonds. Bands in the $900-600 \mathrm{~cm}^{-1}$ are attributed to the out of plane bending of the ring $\mathrm{C}-\mathrm{H}$ bonds (Silverstein et al 1991).

The X-ray diffractograms of $\mathrm{ZW}$ and $\mathrm{ZWpCP}$ do not show any sharp bands. Thus, no conclusions regarding the crystallinity of the materials/layered material could be made.
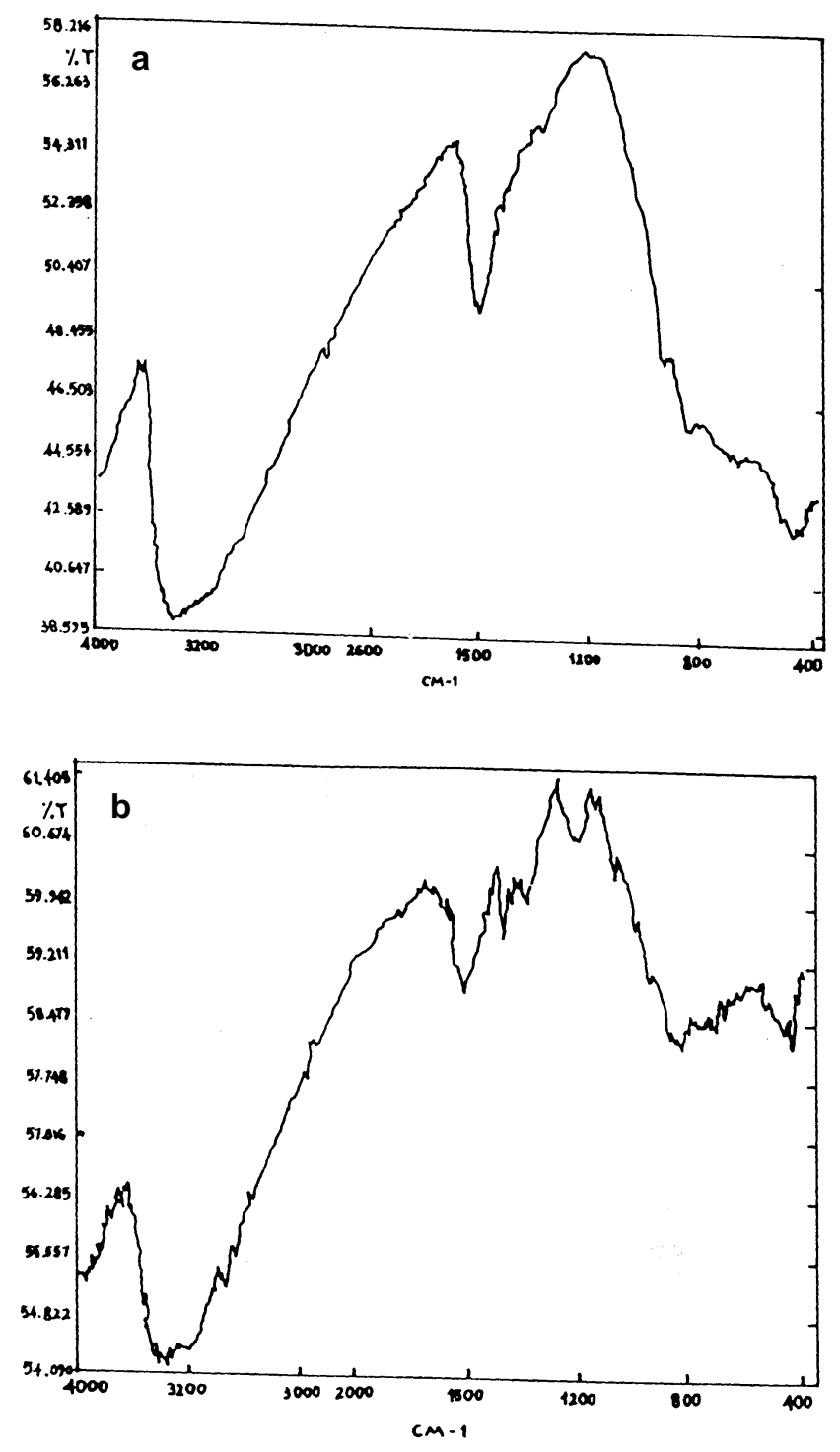

Figure 1. FTIR spectra of a. $\mathrm{ZW}$ and b. $\mathrm{ZW} p \mathrm{CP}$. 
As mentioned earlier in the introduction, derivatization in case of layered TMA salts occurs through intercalation whereas in non-layered materials, organic molecules get either sorbed or anchored to the surface or get encapsulated within the pores of the inorganic matrix. So far as the nature of bonding of the organic moiety with the inorganic matrix is concerned, it could be either weak vander waals forces, encapsulation, hydrogen bonding, covalent bonding or a strong ionic interaction, resulting into the localization of the attractive forces (Singh et al 1985; Khan and Singh 1987; Varshney et al 1993).

Several research groups have commented on the nature of interaction of the organic guests with the inorganic matrix. In case of the layered TMA salts, the organic moieties interact with the inorganic matrix through vander waals forces or hydrogen bonding as revealed by the IR and TGA data (Alberti et al 1979; Dines and Digiacomo 1981). Interaction of amino acids such as L-asparagine and L-alanine onto crystalline TMA salt $\mathrm{ZrP}$ is suggested to occur through an ion exchange reaction (Kijima et al 1981). The adsorption of organic molecules such as phosphamidon and carbofuran occurs through the localization of the attractive forces, between the surface protons of the inorganic matrix and the $-\mathrm{CO}$ and $-\mathrm{PO}$ groups of the organic molecules (Singh et al 1985; Khan and Singh 1987; Varshney et al 1993). Anchoring of organic molecules such as sodium salts of chromotropic acid (1,8-dihydroxynapthalene-3,6-disulphonic acid) and tiron (1,2-dihydroxy-benzene-3,5-disulphonic acid) have been investigated in our laboratory (Pandit and Chudasama 1996, 1998). These salts possessing $-\mathrm{OH}$ as well as $-\mathrm{SO}_{3} \mathrm{Na}$ groups are attached by ion exchange.

In the present study, the interaction of the para chlorophenol $(p \mathrm{CP})$ on the $\mathrm{ZW}$ matrix is proposed on the basis of the FTIR data. IR spectrum of neat $p$ CP consists of a sharp band between $\sim 1060 \mathrm{~cm}^{-1}$ and $1010 \mathrm{~cm}^{-1}$ attributed to the presence of an aryl chloride group. This band disappears in the FTIR spectrum of $\mathrm{ZWpCP}$, which indicates that the bonding of the chlorophenol on the inorganic matrix may be through the $-\mathrm{OH}$ of the inorganic $\mathrm{ZW}$ matrix and the chloro group of the $p \mathrm{CP}$, with the elimination of an $\mathrm{HCl}$ molecule. This has been represented schematically as follows:

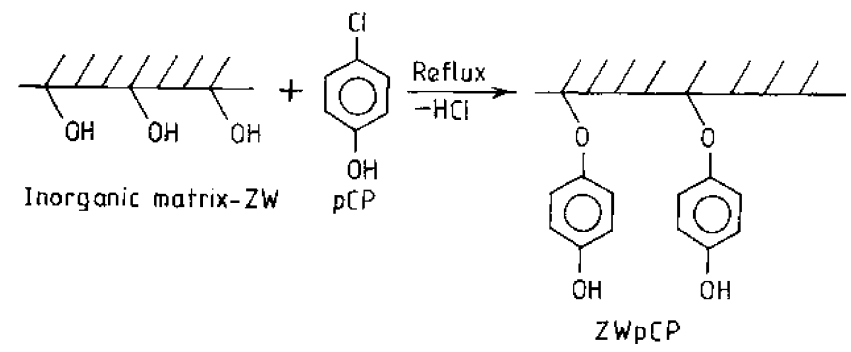

The TGA of ZW (figure 2a) indicates presence of hydrated water which is lost slowly between 100 and $180^{\circ} \mathrm{C}$. TGA of $\mathrm{ZWpCP}$ (figure 2b) indicates a weight loss at $\sim 56^{\circ} \mathrm{C}$ due to traces of solvent used for washing the exchanger after refluxing. There is a gradual decrease in weight up to $500^{\circ} \mathrm{C}$ indicative of the dissociation and decomposition of the organic moiety from the support and the condensation of the structural hydroxyl groups.

The ion exchange capacity (IEC) of ZW at room temperature is $0.58 \mathrm{meq} \mathrm{g}^{-1}$ whereas that of $\mathrm{ZWpCP}$ is $0 \cdot 80 \mathrm{meq} \mathrm{g}^{-1}$. A higher value of IEC in case of $\mathrm{ZWpCP}$ is due to the additional exchangeable $\mathrm{H}^{+}$sites, created due to anchoring of $p \mathrm{CP}$ on $\mathrm{ZW}$, the electron withdrawing phenyl ring making the phenolic $(-\mathrm{OH})$ protons more labile.

The results of the effect of heating on IEC are summarized in table 1 . For $\mathrm{ZW}$, the IEC decreases on heating. This is due to the condensation of the structural hydroxyl groups bearing the exchangeable protons, at higher temperatures. However, in case of $\mathrm{ZWpCP}$, the IEC decreases up to $200^{\circ} \mathrm{C}$ and then increases for the sample heated at $300^{\circ} \mathrm{C}$. Again for the samples heated at $400^{\circ} \mathrm{C}$ and $500^{\circ} \mathrm{C}$,
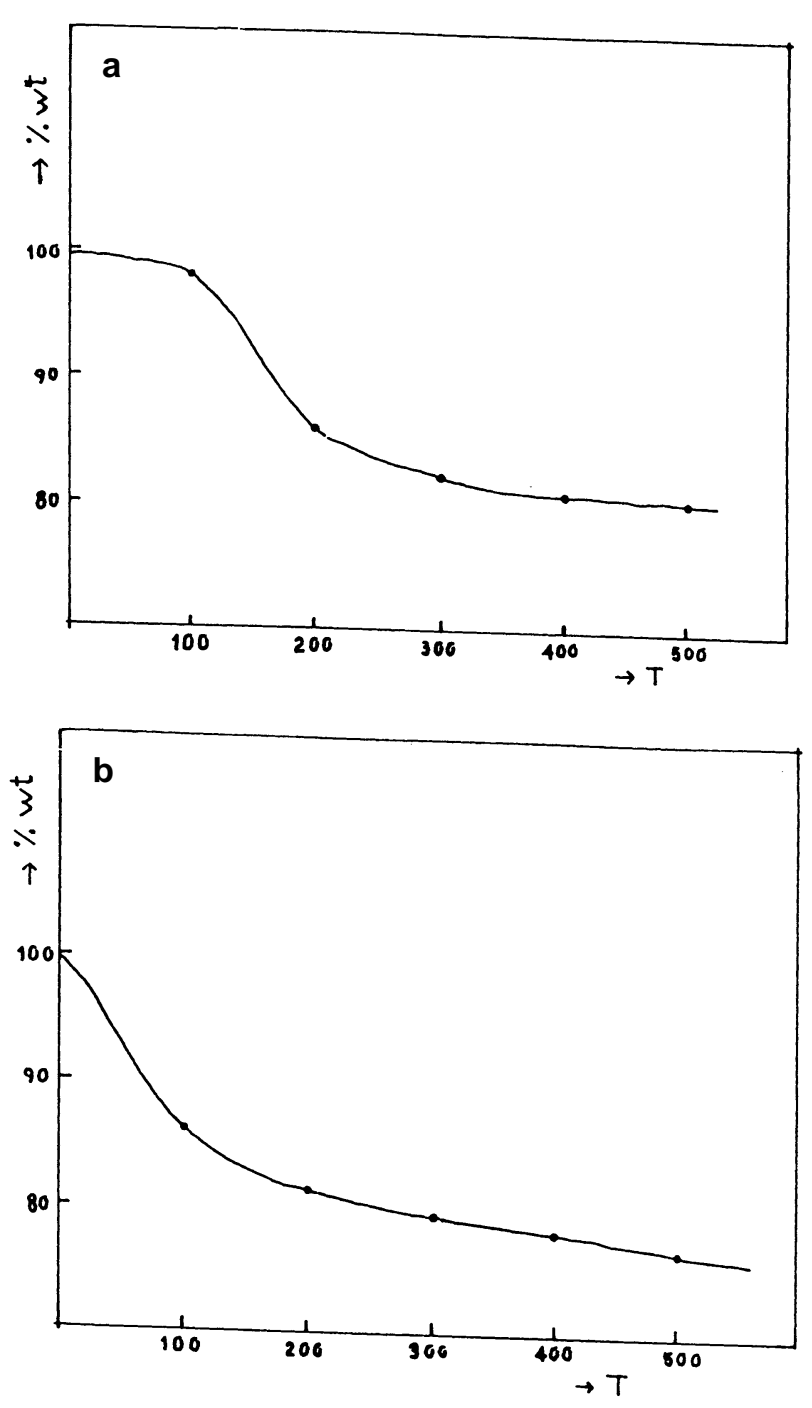

Figure 2. TGA of a. $\mathrm{ZW}$ and b. $\mathrm{ZW} p \mathrm{CP}$. 
Table 1. Effect of heating on IEC of $\mathrm{ZW}$ and $\mathrm{ZW} p \mathrm{CP}$.

\begin{tabular}{|c|c|c|c|c|}
\hline \multirow[b]{2}{*}{ Temperature $\left({ }^{\circ} \mathrm{C}\right)$} & \multicolumn{2}{|c|}{ Colour change } & \multicolumn{2}{|c|}{$\operatorname{IEC}\left(\right.$ meq $\left.\cdot \mathrm{g}^{1}\right)$} \\
\hline & ZW & $\mathrm{ZWpCP}$ & ZW & $\mathrm{ZWpCP}$ \\
\hline R.T. & White & Yellowish brown & 0.58 & $0 \cdot 80$ \\
\hline 100 & Light brown & Brown & $0 \cdot 40$ & $0 \cdot 42$ \\
\hline 200 & Light brown & Black & $0 \cdot 36$ & $0 \cdot 22$ \\
\hline 300 & White & Black & $0 \cdot 26$ & 0.56 \\
\hline 400 & White & Dark brown & $0 \cdot 24$ & $0 \cdot 54$ \\
\hline 500 & White & White & $0 \cdot 22$ & $0 \cdot 50$ \\
\hline
\end{tabular}

Table 2. Effect of electrolyte concentration on $K_{\mathrm{d}}$ values of metal ions for $\mathrm{ZW} p \mathrm{CP}$.

\begin{tabular}{|c|c|c|c|c|c|c|c|}
\hline Metal ion & D.W. & $0 \cdot 01 \mathrm{M} \mathrm{HNO}_{3}$ & $0 \cdot 1 \mathrm{M} \mathrm{HNO}_{3}$ & $0.4 \mathrm{M} \mathrm{HNO}_{3}$ & $0.05 \mathrm{M} \mathrm{NH}_{4} \mathrm{NO}_{3}$ & $0.5 \mathrm{M} \mathrm{NH}_{4} \mathrm{NO}_{3}$ & $1 \mathrm{M} \mathrm{NH}_{4} \mathrm{NO}_{3}$ \\
\hline $\mathrm{Cu}^{2+}$ & 89.62 & N.S.* & N.S. & N.S. & $20 \cdot 69$ & N.S. & N.S. \\
\hline $\mathrm{Zn}^{2+}$ & $11 \cdot 05$ & $11 \cdot 05$ & N.S. & N.S. & $10 \cdot 23$ & N.S. & N.S. \\
\hline $\mathrm{Co}^{2+}$ & $10 \cdot 53$ & $10 \cdot 51$ & $9 \cdot 66$ & 9.00 & N.S. & N.S. & N.S. \\
\hline $\mathrm{Mn}^{2+}$ & 52.63 & $15 \cdot 31$ & N.S. & N.S. & $33 \cdot 15$ & $22 \cdot 1$ & $22 \cdot 1$ \\
\hline $\mathrm{Ni}^{2+}$ & $11 \cdot 29$ & N.S. & N.S. & N.S. & $10 \cdot 54$ & $9 \cdot 26$ & N.S. \\
\hline $\mathrm{Pb}^{2+}$ & $9 \cdot 39$ & $9 \cdot 39$ & $9 \cdot 39$ & N.S. & $9 \cdot 30$ & $9 \cdot 30$ & $8 \cdot 62$ \\
\hline $\mathrm{Hg}^{2+}$ & $6 \cdot 84$ & $5 \cdot 14$ & $5 \cdot 14$ & $5 \cdot 14$ & $6 \cdot 23$ & N.S. & N.S. \\
\hline $\mathrm{Bi}^{3+}$ & $11 \cdot 05$ & $11 \cdot 05$ & $5 \cdot 67$ & N.S. & $11 \cdot 05$ & $10 \cdot 89$ & $6 \cdot 02$ \\
\hline $\mathrm{La}^{3+}$ & $19 \cdot 85$ & N.S. & N.S. & N.S. & N.S. & N.S. & N.S. \\
\hline $\mathrm{Ce}^{4+}$ & $20 \cdot 40$ & $10 \cdot 64$ & $9 \cdot 87$ & $7 \cdot 32$ & $19 \cdot 85$ & $19 \cdot 00$ & 8.67 \\
\hline $\mathrm{Th}^{4+}$ & $65 \cdot 67$ & $33 \cdot 39$ & $30 \cdot 52$ & $15 \cdot 13$ & $12 \cdot 63$ & N.S. & N.S. \\
\hline
\end{tabular}

*N.S.: No sorption.

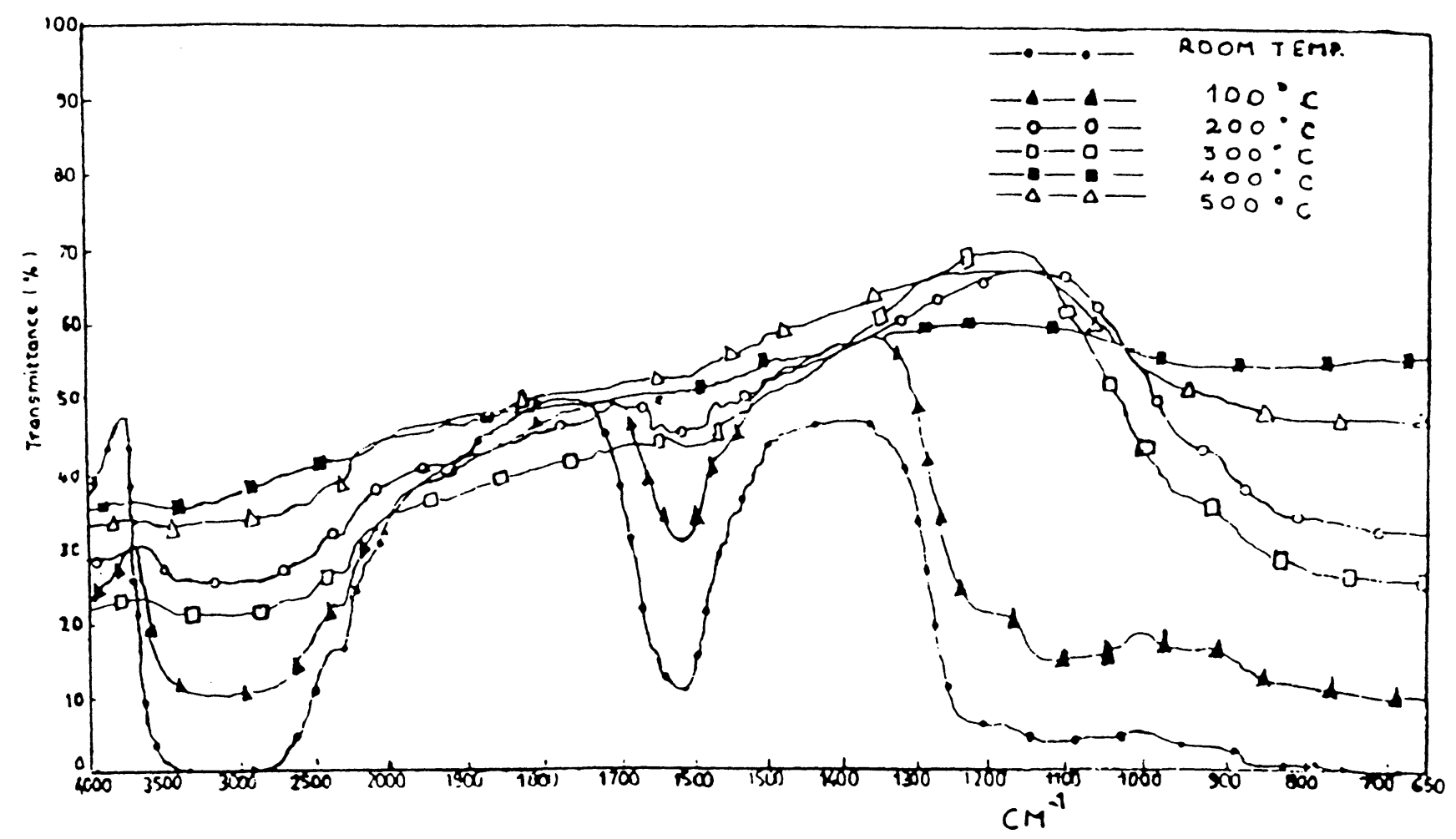

Figure 3. IR spectra of $\mathrm{ZW}$ heated at various temperatures. 


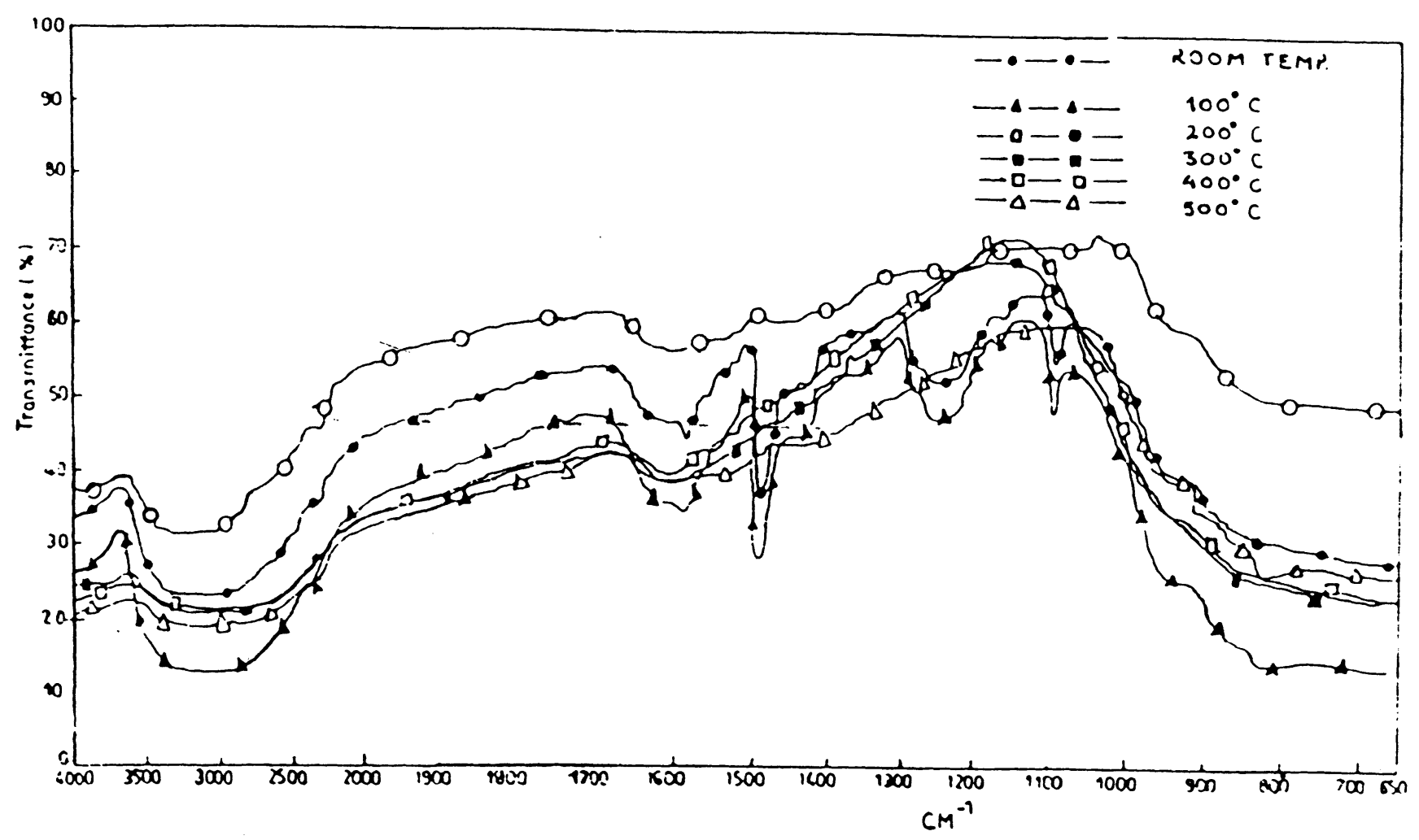

Figure 4. IR spectra of $\mathrm{ZWp} P \mathrm{CP}$ heated at various temperatures.

Table 3. Metal ion separation for $\mathrm{ZW} p \mathrm{CP}$.

\begin{tabular}{llccc}
\hline Separation achieved & \multicolumn{1}{c}{ Eluants } & $\begin{array}{c}\text { Amount loaded } \\
(\mathrm{mg})\end{array}$ & $\begin{array}{c}\text { Amount eluted } \\
(\mathrm{mg})\end{array}$ & $\begin{array}{c}\% \\
\text { efficiency }\end{array}$ \\
\hline 1. $\mathrm{Co}(\mathrm{II})-\mathrm{Cu}(\mathrm{II})$ & $0.05 \mathrm{M} \mathrm{NH}_{4} \mathrm{NO}_{3}(\mathrm{Co})$ & 0.3890 & 0.3812 & $98 \cdot 00$ \\
& $0.01 \mathrm{M} \mathrm{HNO}_{3}(\mathrm{Cu})$ & 0.4196 & 0.3941 & 93.90 \\
2. $\mathrm{Co}(\mathrm{II})-\mathrm{Zn}(\mathrm{II})$ & $0.05 \mathrm{M} \mathrm{NH}_{4} \mathrm{NO}_{3}(\mathrm{Co})$ & 0.3890 & 0.3656 & $94 \cdot 00$ \\
& $0.01 \mathrm{M} \mathrm{HNO}_{3}(\mathrm{Zn})$ & 1.0425 & 0.9382 & $90 \cdot 00$ \\
$3 . \mathrm{Co}(\mathrm{II})-\mathrm{Pb}(\mathrm{II})$ & $0.05 \mathrm{M} \mathrm{NH}_{4} \mathrm{NO}_{3}(\mathrm{Co})$ & 0.3890 & 0.3301 & 84.85 \\
& $0.5 \mathrm{M} \mathrm{HNO}_{3}(\mathrm{~Pb})$ & 1.0567 & 1.0360 & 98.04 \\
\hline
\end{tabular}

the IEC decreases. This may be due to the fact that on heating in the range $200-300^{\circ} \mathrm{C}$, the organic moiety decomposes, leading to the formation of active carbon as evidenced by the change in colour of the sample to black. This is responsible for an increase in the IEC and is later lost as $\mathrm{CO}_{2}$ as the heating temperature increases. The fact is also evident from the IR spectra of heated samples (figures 3 and 4) of $\mathrm{ZW}$ and $\mathrm{ZWpCP}$. The intensity of the bands corresponding to $\mathrm{OH}$ groups and the organic moiety decreases.

The distribution coefficient $\left(K_{\mathrm{d}}\right)$ calculated for the metal ions in different electrolyte concentrations for $\mathrm{ZWpCP}$ are summarized in table 2. On the basis of the selective affinity for particular metal ions in the presence of electrolytes, the metal ion $\mathrm{Co}(\mathrm{II})$ has been separated from $\mathrm{Cu}(\mathrm{II}), \mathrm{Zn}$ (II) and $\mathrm{Pb}(\mathrm{II})$. In all the separations $\mathrm{Co}(\mathrm{II})$ was eluted using $0.05 \mathrm{M} \mathrm{NH}_{4} \mathrm{NO}_{3}$ while $\mathrm{Cu}(\mathrm{II}), \mathrm{Zn}(\mathrm{II})$, and $\mathrm{Pb}$ (II) were eluted using 0.01 and $0.4 \mathrm{M} \mathrm{HNO}_{3}$ solutions respectively. The results of the separation study are summarized in table 3 .

\section{Conclusions}

ZWpCP exhibits good ion exchange capacity and is stable up to a fairly high temperature, besides exhibiting stability in different acidic, basic and organic media. Its selectivity for particular metal ions enables it to act as an efficient ion exchanger for the separation of $\mathrm{Co}$ (II) from $\mathrm{Cu}$ (II), $\mathrm{Zn}$ (II) and $\mathrm{Pb}(\mathrm{II})$ with $94-98 \%$ efficiency. The DTMA, $\mathrm{ZWpCP}$ thus exhibits the characteristics of a promising ion exchanger. 


\section{Acknowledgements}

Thanks are due to the Head, Department of Applied Chemistry, for providing necessary laboratory facilities. One of the authors (BP) is also thankful to the M.S. University of Baroda, Vadodara for providing a fellowship.

\section{References}

Alberti G 1990 Pillared layered structures: Current trends and applications (ed.) I V Mitchell (London: Elsevier) p. 119

Alberti G and Torracca E 1972 J. Inorg. Nucl. Chem. 34 2643

Alberti G and Costantino U 1982 Intercalation chemistry (New York: Academic Press Inc.) p. 147

Alberti G and Costantino U 1991 Inclusion compounds (ed.) J L Atwood, J E D Davies and D D Mc Nicol (Oxford: Oxford University Press) Vol. 5, Ch. 5

Alberti G and Casciola M 1997 Solid State Ionics 97177

Alberti G, Casciola U, Allulli S and Tomassini Luciani M L 1978 J. Inorg. Nucl. Chem. 401113

Alberti G, Costantino U and Giovagnotti Luciani M L $1979 \mathrm{~J}$. Chromatogr. 18045

Alberti G, Costantino U and Giovagnotti Luciani M L $1980 \mathrm{~J}$. Inorg. Nucl. Chem. 41643

Alberti G, Costantino U, Kornyei J and Giovagnotti Luciani M L 1982 Chim. Ind. (Milan) 64115

Alberti G, Costantino U, Kornyei J and Giovagnotti Luciani M L 1985 React. Polym. 51

Alberti G, Costantino U, Vivani R and Biswas R K 1992 React. Polym. 17245

Alberti G, Costantino U, Vivani R and Zappelli P 1993a Angew. Chem. Int. Ed. Engl. 321357

Alberti G, Vivani R, Biswas R K and Murcia Mascaros S 1993b React. Polym. 191

Alberti G, Marmottini F, Murcia Mascaros S and Vivani R 1994 Angew. Chem. Int. Ed. Engl. 331594
Amphlett C B 1964 Inorganic ion exchangers (Amsterdam: Elsevier)

Behrendt D, Beneke K and Lagaly G 1976 Angew. Chem. Int. Ed. Engl. 15544

Bringley J F and Averill B A 1990 Chem. Mater. 2180

Clearfield A and Stynes J A 1964 J. Inorg. Nucl. Chem. 26117

Costantino U 1979 J. Chem. Soc. Dalton Trans. 402

Costantino U, Massucci M A, LaGinestra A, Tarola A M and Zampa L 1986 J. Incl. Phenom. 4147

Dines M B and Digiacomo P M 1981 Inorg. Chem. 2092

Elving Ph J and Olson E C 1955 Anal. Chem. 271817

Keller S W, Kim H N and Mallouk T E 1994 J. Am. Chem. Soc. 1168817

Khan A A and Singh R P 1987 Colloids and Surfaces 2433

Kijima T, Sekikawa Y and Ueno S 1981 J. Inorg. Nucl. Chem. 43849

Kleinfield E R and Ferguson G S 1994 Science 265370

Nabi S A and Rao R K 1981 J. Indian Chem. Soc. 111030

Ozin G A 1992 Adv. Mater. 4612

Pandit B and Chudasama U 1996 J. Chem. Res. (S) 484

Pandit B and Chudasama U 1998 Colloids and Surfaces A 132145

Silverstein R M, Bassler G C and Morrill T C 1991 Spectrometric identification of organic compounds (New York: John Wiley and Sons Inc.) 5th ed., Ch. 3

Singh R P, Varshney K G and Rani S 1985 Ecotoxicol. Environ. Saf. 10309

Szirtes L, Kornyei J and Poko Z 1988 React. Polym. 7185

Varshney K G and Khan A M 1991 Inorganic ion exchangers in chemical analysis (ed.) M Qureshi and K G Varshney (Florida: CRC Press Boca Raton)

Varshney K G, Khan A A, Gupta U and Maheshwari S M 1993 Colloids and Surfaces 69265

Varshney K G and Hussain P A 1996 Chem. Environ. Res. 5141

Vermuelen L A and Thompson M E 1992 Nature 358656

Vogel A I 1978 Textbook of quantitative inorganic analysis (London: Longman Green) IV ed.

Vogel A I 1989 Elementary practical organic chemistry, Part III, quantitative chemistry (London: ELBS and Longman Group Ltd.) 